\title{
AB INITIO STUDY, INVESTIGATION OF NMR SHIELDING TENSORS, NBO AND VIBRATIONAL FREQUENCY OF CATECHOL THIOETHERS
}

\author{
A. Bagheri $\mathrm{Gh}^{*}$ \\ Department of Chemistry, Center Tehran Branch, Islamic Azad University, Tehran, Iran
}

(Received January 19, 2009; revised January 10, 2010)

\begin{abstract}
The electrochemical oxidation of dopamine and 3,4-dihydroxymethamphetamine (HHMA) has been studied in the presence of GSH and cysteine as a nucleophile. In order to determine the optimized geometries, energies, dipole moments, atomic charges, thermochemical analysis and other properties, we performed quantum chemical ab initio and density functional calculations at B3LYP level with 6-31G* basis set. The structural and vibrational properties of 5-S-glutathionyldopamine, 5-S-cysteinyldopamine and 5-S-Nacetylcysteinyldopamine are studied. The chemical shifts of anisotropy and $\Delta \delta$ are calculated. The gaugeinvariant atomic orbital (GIAO) method was employed to calculate isotropic atomic shielding of compounds. These calculations yield molecular geometries in good agreement with available experimental data. The bond lengths, bond angles, dipole moment, electron affinity, ionization potential, electronegativy, absolute hardness, highest occupied molecular orbital (HOMO) and the energy of the lowest unoccupied molecular orbital (LUMO) of the studied compounds were calculated in gas phase and water. NMR analysis of dopamine-o-quinoneglutathione conjugate revealed that the addition of glutathione was at C-5 to form glutathionyl-dopamine.
\end{abstract}

KEY WORDS: Catechol thioether, Dopamine, NMR, GIAO, B3LYP, NBO

\section{INTRODUCTION}

Catechol autoxidation is particularly interesting because the resulting $o$-quinones are chemically reactive toward several cellular nucleophiles, with thiolates being greatly favored kinetically. Indeed, adduction by thiolates occurs more rapidly than $o$-quinone reduction by ascorbate [1]. The products of thiolate addition to $o$-quinones are called catechol thioethers. In biological systems, catechol thioethers form mostly with free cysteine, GSH, or protein-bound cysteine [2]. Catechol thioethers may also be formed from norepinephrine by similar chemical reactions [3]; however, most research effort has been directed at catechol thioethers derived from dopamine and its metabolites. Glutathionyl and cysteinyl catechol thioethers derived from dopamine and 3,4-dihydroxyphenylacetic acid (DOPAC) have been identified as the major non-protein-bound catechol thioethers in the striatum and midbrain of humans and other mammals. In fact, the cysteinyl catechol thioethers have been studied as biomarkers of catechol oxidation. Increased levels of 5-S-cysteinyldopamine (Cys-dopamine) and 5-S-cysteinyl-DOPAC (Cys-DOPAC) in midbrain and striatum have been associated with nigral degeneration, advancing age, and oxidant stress [4]. Hence, it has been proposed that catechol thioether formation contributes to dopaminergic neurodegeneration by depleting GSH [5]. Alternatively, catechol thioethers may also act directly or indirectly as endogenous neurotoxins. The physiological relevance of GSH conjugation of o-quinones derived from catecholamines depends upon the existence of these metabolites in vivo. The conjugate 5-S-glutathionyldopamine is the precursor of 5-Scysteinyldopamine. Indeed, 5-S-cysteinyldopamine has been detected in cerebrospinal fluid of PD patients and control subjects by using HPLC [6]. The physiological relevance of GSH conjugation of dopamine $o$-quinine to 5 -S-glutathionyldopamine as a neuroprotective reaction is supported by the finding that formation 5-S-glutathionyl- and 5-S-cysteinyl-dopamine prevented dopamine-mediated DNA damage in a dose dependent manner [7].

*Corresponding author. E-mail: azbagheri@gmail.com 
Over the past 20 years, $( \pm)$-3,4-methylenedioxymethamphetamine (MDMA) has gained great popularity as a recreational drug, mainly among young people, due to its stimulant and hallucinogenic properties [8]. However, there are many concerns over its short-term and longterm effects. First, abuse of MDMA is associated with the risk of severe, sometimes fatal, intoxication [9]. Second, there is considerable evidence to indicate that MDMA has neurotoxic potential toward brain serotonergic and/or dopaminergic nerve terminals [10].

MDMA metabolism proceeds via two pathways, which operate in unison but at different rates, deponding on species [11]. In humans, MDMA is essentially metabolized, through Odemethylenation, into 3,4-dihydroxymethamphetamine (HHMA), whereas $\mathrm{N}$-demethylation leading to 3,4-methylenedioxyamphetamine (MDA) constitutes a minor metabolic route (Scheme 1) [12]. Because of its catechol moiety, HHMA can be easily oxidized to the corresponding $o$-quinone species which exhibits a double reactivity. First, it can undergo redoxcycling which originates semiquinone radical and leads to the generation of reactive oxygen species. Second, it behaves as a highly electrophilic compound which can be conjugated with thiol nocleophils such as glutathione (GSH), to from the 5-(glutathione-S-yl) mono-conjugate.
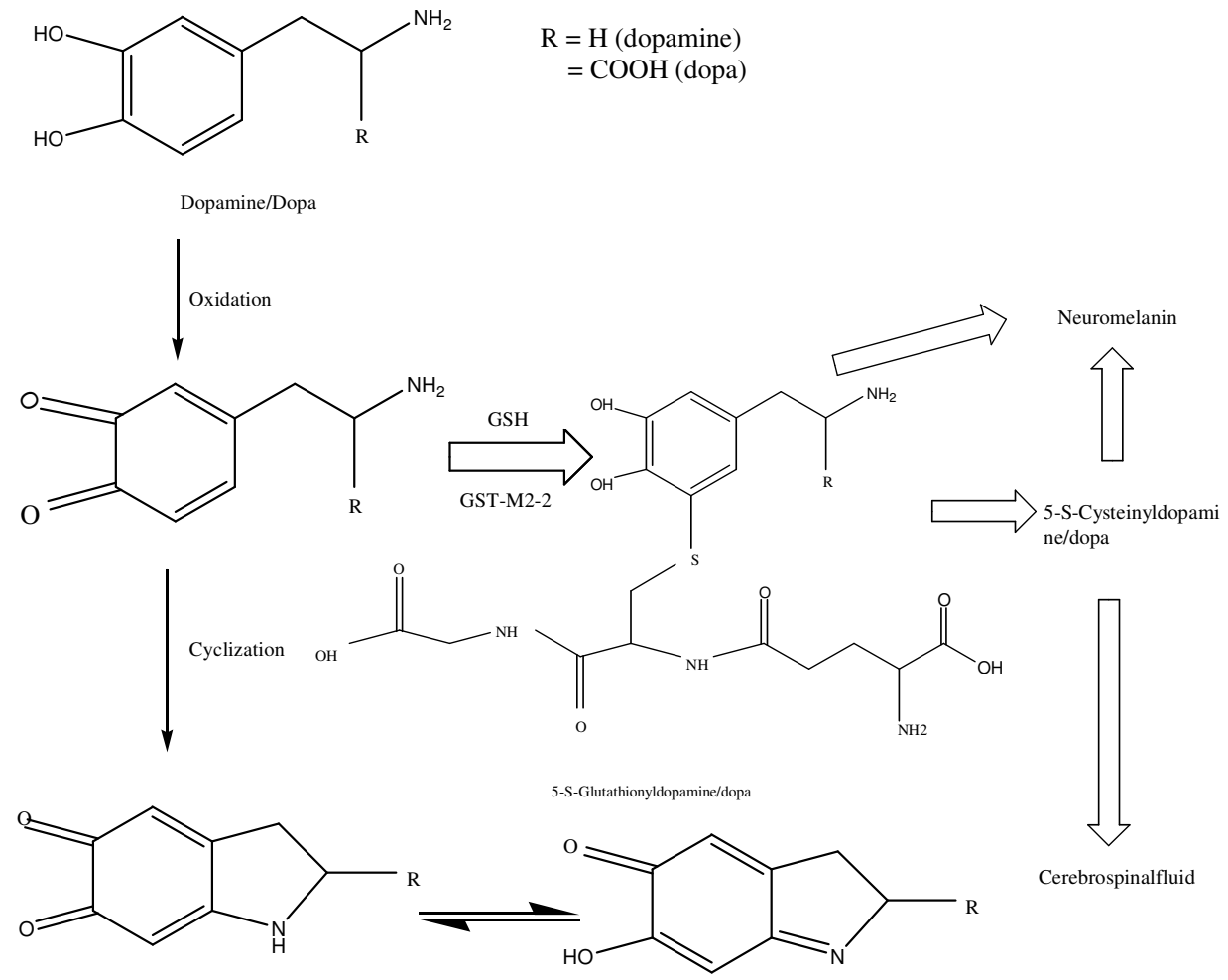

Aminochrome/dopachrome

Scheme 1. Proposed antioxidant and neuroprotective conjugation of dopamine and HHMA $o$-quinone catalyzed by GST M2-2. 
A few studies have investigated the potential biological activity of catechol thioethers and their products. The GSH conjugation of the o-quinones of dopamine and dopamine is an important antioxidant and neuroprotective reaction, which may have relevance in the prevention of degenerative processes of the dopaminergic system in human brain. Therefore, with the aim of investigation of reactivity of dopamine toward thiols, we investigated the electrochemical oxidation of dopamine and HHMA in presence of GSH, cys or acscys.

\section{COMPUTATIONAL METHODS}

The system used in calculations consists of dopamine and HHMA in presence of GSH, cys or acscys.

All the systems were optimized at B3LYP density functional theory (DFT), using the Gaussian $98[13,14]$ suite of program has performed the calculations. NBO calculations have been done at the B3LYP/6-31G* /6-31G* method. The second-order perturbative estimates of donor-acceptor (bond-antibond) interactions have been done on the NBO basis $[15,16]$. This was carried out by examining all possible interactions between filled (donor) Lewis type NBOs and empty (acceptor) non-Lewis NBOs and estimating their energetic importance by two second-order perturbation theory. Since these interactions lead to loss of occupancy from the localized NBOs of the idealized Lewis structure into the empty non-Lewis orbitals (and thus, to departures from the idealized Lewis structure description), they are referred to as delocalization corrections to the zeroth-order natural Lewis structure. For each donor NBO (i) and acceptor NBO (j) the stabilization energy E (2) associated with delocalization (2e-stabilization) $\mathrm{i} \rightarrow \mathrm{j}$ is estimated as

$$
E(2)=\Delta E_{i j}=q_{i} /\left[F(i, j)^{2}(\varepsilon i-\varepsilon j)\right]
$$

where $\mathrm{q}_{\mathrm{i}}$ is the donor orbital occupancy, $\varepsilon i$ and $\varepsilon j$ are diagonal elements (orbital energies) and $\mathrm{F}(\mathrm{i}, \mathrm{j})$ is the off-diagonal NBO Fock matrix element.

All NMR analysis have been performed using 6-31g* basis set and HF and B3LYP levels. GIAO methods $[17,18]$ are used to calculate the isotropic NMR shielding at the B3LYP/6$31 \mathrm{~g} * \mathrm{HF} / 6-31 \mathrm{~g} *$ of theory.

Interaction energies $(\Delta \mathrm{E})$ are calculated due to the difference between the total energies of adducts with the sum of the components.

The variation in zero point energies were considered together thermochemical analysis at $298 \mathrm{~K}$ in order to obtain entropy $(\Delta \mathrm{S})$ and free energy $(\Delta \mathrm{G})$ variation for the considered process. Bond enthalpies at $298 \mathrm{~K}$ and $1 \mathrm{~atm}(\mathrm{H})$ were calculated from $0 \mathrm{~K}$ electronic bond (E) assuming an ideal gas:

$$
\Delta \mathrm{H}_{298}=\Delta \mathrm{E}+\Delta \mathrm{E}_{\text {trans }, 298}+\Delta \mathrm{E}_{\mathrm{rot}, 298}+\Delta \mathrm{E}_{\mathrm{vib}}+\Delta(\mathrm{PV})
$$

Here $\Delta \mathrm{E}_{\text {trans,298, }} \Delta \mathrm{E}_{\text {rot,298 }}$ and $\Delta \mathrm{E}_{\text {vib }}$ are the differences between products and reactants in translational, rotational and zero-point vibrational energy corrections are based on our frequency calculations. The molar work term $\Delta(\mathrm{PV})$ is $(\Delta \mathrm{n}) \mathrm{RT} ; \Delta \mathrm{n}=-1$ for two fragments combining to one molecule.

$\mathrm{Ab}$ initio calculation of nuclear magnetic shielding has become an indispensable aid in the investigation of molecular structure and accurate assignment of NMR spectra of compounds.

\section{RESULTS AND DISCUSSION}

The oxidative pathway of dopamine metabolism in the human brain leads to the formation and accumulation of neuromelanin in the cytoplasm of most nigrostriatal dopaminergic neurons

Bull. Chem. Soc. Ethiop. 2010, 24(2) 
[19]. The biosynthesis, structure and physiological functions of neuromelanin in the human substantia nigra are not well understood so far. It is generally accepted that the pigment synthesis starts from the oxidation of dopamine (DA) to its o-quinone, which easily undergoes intramolecular cyclization and further oxidation to dopaminochrome. The rearrangement of dopaminochrome to 5,6-dihydroksyindole, and subsequently oxidative polymerization of the latter compound lead to the formation of indolic eumelanin. In vitro studies major product [20], 5-S-CysDA is more easily oxidized than DA to form benzothiazine derivatives [21]. Such reactions are believed to occur under physiological conditions because 5-S-CysDA has been detected in certain dopaminergic regions of brain (including substantia nigra) and in cerebrospinal fluid of normal human subjects [22]. Moreover, degradative studies of neuromelanin isolated from human substantia nigra have indicated a significant incorporation of 5-S-CysDA-derived units into the polymer. DA $o$-quinone is also efficiently conjugated with reduced glutathione to form 5-S-glutathionyldopamine [20]. Although this conjugate has not been detected in the brain, it is postulated that 5-S-CysDA may result from hydrolysis of 5-Sglutathionyldopamine by intraneuronal peptidase enzymes [23].

It is not clear whether the conversion of dopamine into neuromelanin in vivo requires an enzyme contribution. Peroxidase [24], monoamine oxidase, lipoxygenase [25] and prostaglandin $\mathrm{H}$ synthetase [26] have been suggested to be involved in neuromelanin biosynthesis. On the other hand, it has been postulated that neuromelanin formation is an autoxidative process mediated by reactive oxygen species. Heavily melanized dopaminergic neurons of the nigrostriatal pathway are known to be particularly susceptible to oxidative stress and degeneration in Parkinson's disease [27]. The contribution of neuromelanin to the pathogenesis of Parkinson's disease [28] is still an open question. In vitro studies have demonstrated that the pigment could act either as an antioxidant or as a peroxidation-stimulating factor $[29,30]$.

The conjugation of dopamine $o$-quinone to 5-S-glutathionyldopamine can be the precursor reaction of 5-S-cysteinyldopamine. In the rat brain it has been demonstrated that 5-Sglutathionyldopamine conjugate is rapidly metabolized to 5-S-cysteinyldopamine in reaction mediated by gama-glutamyl transpeptidase (gamma-GT) and cysteine conjugate $\mathrm{N}$ acetyltransferase. Therefore, it seems plausible that 5-S-glutathionyldopamine can be converted by gamma-GT and $\mathrm{N}$-acetyltransferase to form 5-S-cysteinyldopamine. 5-S-cysteinyldopamine has been detected in cerebrospinal fluid of Parkinson's disease patitents and control subjects.

5-S-cysteinyldopamine has been reported to be the main source of the pheomelanin moiety of human neuromelanin isolated from the substanita nigra.

\section{Reaction mechanism and reaction pathway}

The dihydroxyindoles are oxidized and quinines appear that can react with other molecules through positions 2,5 and 6 . Amines and thiols groups react by a nucleophilic attack at position 5 or 6 of the ring, due to the blockage of position 2. GSTs are a ubiquitous family of multifunctional proteins. As enzymes, they catalyze the nucleophilic addition of reduced cysteinyl thiol or GSH to a wide variety of hydrophobic electrophiles, including quinones, as well as epoxides, organic halides and activated alkenes

$\mathrm{GSH}+$ Electrophile $\rightarrow$ GS-conjugate $+\mathrm{H}_{2} \mathrm{O}$

The electro-oxidation of dopamine and HHMA in the presence of GSH is considered to involve the Micheal acceptor $o$-quinone as an intermediate that could be attached at position 5 or 6 to yield glutathione mono-conjugate. Calculated activation energy of oxidation reactions is 4834.26 $(\mathrm{R}=\mathrm{H}) \mathrm{kcal} / \mathrm{mol}$ and $771.8\left(\mathrm{R}=\mathrm{CH}_{3}\right) \mathrm{kcal} / \mathrm{mol}$. 
Gas phase results

In order to study mechanism of the reactions, structure corresponding to reactants, transition states and products were optimized in level of theory. Figure 1 shows the optimized structures of reactants, intermediates for paths $\mathrm{A}$ and $\mathrm{B}$. Their selected geometrical parameters are given in Table 1. The intermolecular $\mathrm{C}_{5}-\mathrm{S}, \mathrm{C}_{5}-\mathrm{C}_{6}$ and $\mathrm{C}_{5}-\mathrm{C}_{4}$ distances increase in 5-S-glutathionyldopamine. Characterizations of these bonds have been studied by the NBO method.

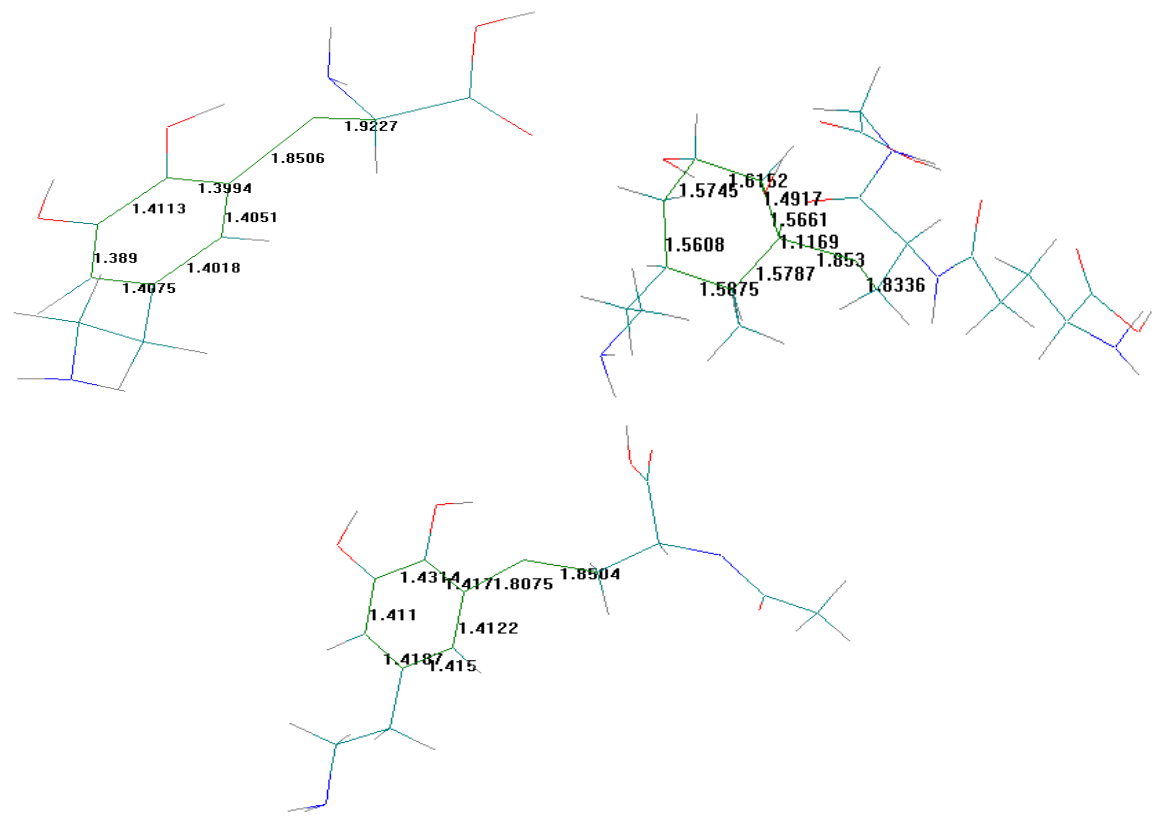

Figure 1. Optimized structures of 5-S-cysteinyldopamine, 5-S-glutathionyldopamine and 5-S-Nacetylcysteinyldopamine in B3LYP/6-31G* level.

Table 1. Selected geometrical parameters for reactants and products in B3LYP/6-31G* levels of theory (distances in angstrom and angles in degree).

\begin{tabular}{|l|c|c|c|c|c|c|}
\hline Compounds & $\mathrm{C}_{5}-\mathrm{S}$ & $\mathrm{C}_{5}-\mathrm{S}-\mathrm{C}_{\mathrm{GSH}}$ & $\mathrm{C}_{5}-\mathrm{C}_{6}-\mathrm{S}-\mathrm{C}_{\mathrm{GSH}}$ & $\mathrm{C}_{5}-\mathrm{C}_{6}$ & $\mathrm{C}_{5}-\mathrm{C}_{4}$ & $\mathrm{C}_{\mathrm{GSH}}-\mathrm{S}$ \\
\hline 5-S-cysteinyldopamine & 1.851 & 101.15 & 125.40 & 1.405 & 1.399 & 1.923 \\
\hline 5-S-glutathionyldopamine & 1.853 & 98.56 & 85.11 & 1.579 & 1.566 & 1.834 \\
\hline 5-S-N- acetylcysteinyldopamine & 1.807 & 98.11 & 78.72 & 1.412 & 1.417 & 1.805 \\
\hline
\end{tabular}

\section{Thermochemical analysis}

Thermochemical analysis is studied for the compounds. The values of $\Delta H, \Delta S$ and $\Delta \mathrm{G}$ are reported in Table 2. The equilibrium constants of compounds are also given in Table 2 . The $\Delta \mathrm{G}$ value of S-cysteinyldopamine is more than 5-S-glutathionyldopamine which shows the stability of S-cysteinyldopamine is less. 
Table 2. Interaction energy $(\Delta \mathrm{E})$, entropy $(\Delta \mathrm{S})$, enthalpy $(\Delta \mathrm{H})$ and free energy $(\Delta \mathrm{G})$ variations for the formation process at $298 \mathrm{~K}$, computed at B3LYP level of theory.

\begin{tabular}{|l|l|l|l|l|c|}
\hline Compounds & \multicolumn{1}{|c|}{$\Delta \mathrm{E}^{\mathrm{a}}$} & \multicolumn{1}{c|}{$\Delta \mathrm{H}^{\mathrm{a}}$} & \multicolumn{1}{c|}{$\Delta \mathrm{G}^{\mathrm{a}}$} & \multicolumn{1}{c|}{$\Delta \mathrm{S}^{\mathrm{b}}$} & $\mathrm{K}$ \\
\hline 5-S-cysteinyldopamine & -4097.57 & -4099.14 & -4085.025 & -47.75 & 5.20 \\
5-S-glutathionyldopamine & -22884.9 & -22878.65 & -23524.97 & -138.06 & $1.33 \times 10^{4}$ \\
\hline \multicolumn{6}{|c|}{ 5-S-glutathionyldopamine $\rightarrow$ 5-S-cysteinyldopamine } \\
\hline \multicolumn{7}{|c|}{-74992.5} & -74948.6 & -74979.97 & 94.75 & $1.39 \times 10^{13}$ \\
\hline
\end{tabular}

${ }^{\mathrm{a}}$ The values are in $\mathrm{kcal} / \mathrm{mol} .{ }^{\mathrm{b}} \mathrm{The}$ values are in $\mathrm{cal} / \mathrm{mol} . \mathrm{K}$.

The thermochemical values were calculated and are given in Table 3 . The difference of the results of calculation using DFT and HF are not significant, that were shown the robustness and validity of the results. Gibss free energy of quinones is smaller than that of dopamine and HHMA.

Table 3. Calculated thermochemical values.

\begin{tabular}{|l|c|c|c|c|}
\hline Thermochemical parameters & Dopamine & $\begin{array}{c}\text { Dopamine- } \\
o \text {-quinone }\end{array}$ & HHMA & $\begin{array}{c}\text { HHMA-o- } \\
\text { quinone }\end{array}$ \\
\hline Zero-point correction & 115.0264 & 105.2236 & 160.1725 & 143.9811 \\
Thermal correction to energy & 121.9295 & 111.7941 & 168.6413 & 152.2083 \\
Thermal correction to enthalpy & 122.5225 & 112.3865 & 169.2336 & 152.8006 \\
Thermal correction to Gibbs free energy & 91.7367 & 81.8994 & 134.5511 & 118.2976 \\
Sum of electronic and zero-point energies & -323997 & -319163 & -368649 & -367880 \\
Sum of electronic and thermal energies & -323990 & -319157 & -368640 & -367872 \\
Sum of electronic and thermal enthalpies & -323989 & -319156 & -368640 & -367871 \\
Sum of electronic and thermal free energy & -324020 & -319186 & -368674 & -367905 \\
\hline
\end{tabular}

The values are in $\mathrm{kcal} / \mathrm{mol}$.

\section{Population analysis}

The Mulliken population analysis, like all atomic charge assignment schemes, is an arbitrary method for assigning atomic charges. Generally, changes in the Mulliken population provide a reasonable estimation of changes in electron density within closely related molecules. Mulliken population analysis assigns atomic charges by dividing molecular orbital overlap even between each pair of atoms involved in a chemical bond. To identify any artifacts in the Mulliken population analysis, a natural bond orbital was also performed. Charge distribution of selected atoms were calculated by B3LYP/6-31G* method (Table 4). This analysis shows large charges of $\mathrm{C}, \mathrm{C}_{5}$ and $\mathrm{S}$ atoms. Charge on $\mathrm{S}$ atom are increased to positive values in 5-Scysteinyldopamine,

Table 4. Mulliken population of selected atoms at the B3LYP level.

\begin{tabular}{|l|c|c|c|c|}
\hline Compounds & $\mathrm{S}$ & $-\mathrm{C}_{\mathrm{gsh}}$ or $\mathrm{C}_{\mathrm{cys}}$ & $-\mathrm{C}_{5}$ & $-\mathrm{C}_{6}$ \\
\hline 5-S-cysteinyldopamine & 0.3259 & -0.2982 & -0.0477 & - \\
5-S-glutathionyldopamine & 0.1455 & -0.2225 & -0.1540 & - \\
HHMA & - & - & -0.110 & -0.093 \\
Dopamine & - & - & -0.113 & -0.094 \\
HHMA - o-quinone & - & - & -0.090 & -0.073 \\
Dopamine - o-quinone & - & - & -0.090 & -0.071 \\
GSH & 0.096 & - & - & - \\
\hline
\end{tabular}

Bull. Chem. Soc. Ethiop. 2010, 24(2) 
Natural charges of atoms are reported in Table 4. The results in Table 4 shows that in DFT study of 5-S-glutathionyldopamine and 5-S-cysteinyldopamine with decrease of charge of $\mathrm{C}_{5}$ atom and increase of charge of $\mathrm{C}_{\mathrm{gsh}}$ or $\mathrm{C}_{\mathrm{cys}}$, charge of sulfur increase. Also in 5-Sglutathionyldopamine the difference of atom charge of $\mathrm{C}_{5}$ and sulfur is less. Therefore the bonds become weaker. The small interaction energy is also reflected in electron distribution at the atoms and the corresponding charges.

Table 5 summarizes the highest occupied molecular orbital (HOMO), the lowest unoccupied molecular orbital (LUMO) and HOMO and LUMO energy gaps, dipole moment $(\mu)$, ionization potential (I), electron affinity (A), absolute electronegativity $(\chi)$ and absolute hardness $(\eta)$ for compounds calculated at DFT level in 6-31G basis set. The eigenvalues of LUMO and HOMO and their energy gap reflect the chemical activity of the molecule. Then (I-A) is simply the difference in energy between the HOMO and LUMO. Soft molecules have a small energy gap. Low "I" creates a better electron donor and large "A" makes a better electron acceptor.

Tomasi's polarized continuum model (PCM) [31] defines the cavity as a union of represented numerically. PCM has proved usefulness in describing the effects of the solvent on some characteristic of the molecule in solution. A dipole in molecule will induce a dipole in medium, and the electric field applied by the solvent dipole will in turn interact with the molecular dipole, leading to net stabilization. The parameters have changed in water.

Table 5. The calculated amounts of HOMO and LUMO energies, dipole moment $(\mu)$, ionization potential (I), electron affinity (A), absolute electronegativity $(\chi)$ and absolute hardness $(\eta)$ with the DFT/6$31 \mathrm{G}^{*}$ basis set.

\begin{tabular}{|l|l|l|l|l|l|l|}
\hline Compounds & $\begin{array}{l}\mathrm{E}_{\mathrm{LUMO}}-\mathrm{E}_{\mathrm{HOMO}} \\
(\mathrm{eV})\end{array}$ & \multicolumn{1}{|c|}{$\mu$} & \multicolumn{1}{|c|}{$\mathrm{I}$} & \multicolumn{1}{|c|}{$\chi$} & $\eta$ \\
\hline $\begin{array}{l}5-S \text {-cysteinyl- } \\
\text { dopamine } \\
\text { 5-S-glutathionyl- } \\
\text { dopamine }\end{array}$ & 0.145 & 4.6572 & 0.2015 & 0.05623 & 0.1289 & 0.0730 \\
$\begin{array}{l}\text { Dopamine } \\
\text { Dopamine-o- }\end{array}$ & 0.143 & 10.349 & 0.0972 & -0.0469 & 0.0255 & 0.0715 \\
$\begin{array}{l}\text { quinone } \\
\text { HHMA }\end{array}$ & $0.104(0.108)$ & $3.1382(3.85)$ & $0.1307(0.1353)$ & $0.0263(0.0277)$ & $0.0785(0.081)$ & $0.0522(0.0538)$ \\
HHMA-o- & $0.218(0.217)$ & $3.5036(4.43)$ & $0.1184(0.1179)$ & $-0.0996(-0.0989$ & $0.0094(0.0095)$ & $0.1090(0.1084)$ \\
quinone & $0.104(0.107)$ & $3.5964(4.33)$ & $0.1329(0.1361)$ & $0.0288(0.0286)$ & $0.0808(0.0823)$ & $0.0520(0.0537)$ \\
\hline
\end{tabular}

The calculated parameters in water are presented in parenthes.

Table 6 shows the hybridation coefficient of bonds $\mathrm{C}_{\text {ring }}-\mathrm{S}$ and $\mathrm{C}_{\mathrm{gsh}}-\mathrm{S}$ or $\mathrm{C}_{\mathrm{cys}} \mathrm{S}$ involved in formation of adducts in gas phase, calculated by NBO method at B3LYP/6-31G*. NBO calculation shows the $\mathrm{N}$ or $\mathrm{O}$-bonding contribution in the compounds. A filled bonding or lone pair orbital can act as a donor and an empty or filled bonding, antibonding or lone pair orbital can act as acceptor. These interactions can strengthen and weaken bond. For example, a lone pair donor antibonding acceptor orbital interaction will weaken the bond associated with the antibonding orbitals.

Conversely, an interaction with bonding pair as the acceptor will strengthen the bond. Strong electron delocalization in a best Lewis structure will also show up as donor-acceptor interaction. 
Table 6. Hybridation coefficient of bonds calculated by NBO method in B3LYP /6-31G* level.

\begin{tabular}{|l|l|l|}
\hline Compounds & \multicolumn{1}{|c|}{ C5-S16 } & \multicolumn{1}{|c|}{ S16-C21 } \\
\hline 5-S-cysteinyldopamine & $\mathrm{S} 0.6912\left(\mathrm{sp}^{3.25}\right) \mathrm{C} 5+0.7226\left(\mathrm{sp}^{5.51}\right) \mathrm{S} 16$ & $\mathrm{~S} 0.7105\left(\mathrm{sp}^{11.73}\right) \mathrm{S} 16+0.7037\left(\mathrm{sp}^{3.78}\right) \mathrm{C} 21$ \\
5-S-glutathionyldopamine & $\mathrm{S} 0.7340\left(\mathrm{sp}^{3.37}\right) \mathrm{C} 5+0.6792\left(\mathrm{sp}^{12.47}\right) \mathrm{S} 16$ & $\mathrm{~S} 0.7037\left(\mathrm{sp}^{11.73}\right) \mathrm{S} 16+0.7105\left(\mathrm{sp}^{3.78}\right) \mathrm{C} 21$ \\
5-S-N-acetylcysteinyldopamine & $\mathrm{S} 0.7420\left(\mathrm{sp}^{2.82}\right) \mathrm{C} 5+0.6704\left(\mathrm{sp}^{4.42}\right) \mathrm{S} 16$ & $\mathrm{~S} 0.6827\left(\mathrm{sp}^{5.10}\right) \mathrm{S} 16+0.7307\left(\mathrm{sp}^{3.67}\right) \mathrm{C} 21$ \\
\hline
\end{tabular}

Some of the frequency assignments for these compounds are given in Table 7. In Table 7, a very strong band at $1700-1770 \mathrm{~cm}^{-1}$ is assigned to $\mathrm{C}=\mathrm{O}$ stretching vibration of $5-\mathrm{S}$ cysteinyldopamine. Peaks of $2800-3100 \mathrm{~cm}^{-1}$ are assigned to stretching vibration of $\mathrm{CH}$ aromatic ring. Peaks of strong intensity at $3600-3700 \mathrm{~cm}^{-1}$ are assigned to phenol, stretching vibrational of $-\mathrm{NH}_{2}$ group is observed at $3400 \mathrm{~cm}^{-1}$.

Isotropic spectroscopic shielding for all the atoms are reported and chemical shifts of anisotropy of $\mathrm{C}$ and $\mathrm{H}$ are calculated and isotropic shifts of atoms are decreased from isotropic shift of TMS (Table 8).

In Table 8 are shown that oxygens of carboxylate group have lower shifts than hydroxyls. In 5-S-cysteinyldopamine, nitrogen of amine group binding to dopamine have more shift than other compounds. The carbons binding to $\mathrm{OH}$ group have $\Delta \delta$ of more positive than carbon binding to sulfur.

For formation of adducts $\mathrm{C}_{3}$-dopamine were contacted to glutathionyl acid, cysteine and $\mathrm{N}$ acetylcysteine. The comparison of experimental and calculated ${ }^{13} \mathrm{C}$ NMR spectrum of adducts are given in Table 9. These calculations yield molecular geometries in good agreement with available experimental data.

Table 7. Frequencies $\left(\mathrm{cm}^{-1}\right)$ of compounds in B3LYP functional using basis set 6-31G* in gas phase.

\begin{tabular}{|c|c|c|}
\hline 5-S-cysteinyldopamine & 5-S-glutathionyldopamine & 5-S-N-acetylcysteinyldopamine \\
\hline 3623 & 3729 & 3725 \\
3579 & 3390 & 3334 \\
3102 & 3321 & 3202 \\
2824 & 3122 & 3149 \\
2800 & 2834 & 2059 \\
1754 & 1885 & 1969 \\
1699 & 1772 & 1792 \\
1642 & 1691 & 1703 \\
1474 & 1564 & 1661 \\
1414 & 1563 & 1556 \\
1120 & 1429 & 1454 \\
& 1274 & 1381 \\
& 1234 & 1145 \\
\hline
\end{tabular}


Table 8. Isotropic, relative (to TMS) shifts in ppm and parameter of $\Delta \delta$ in HF/6-31G* level.

\begin{tabular}{|c|c|c|c|c|c|c|}
\hline \multirow[t]{2}{*}{ Atom } & \multicolumn{3}{|c|}{ 5-S-cysteinyldopamine } & \multicolumn{3}{|c|}{ 5-S-N-acetylcysteinyldopamine } \\
\hline & $\begin{array}{c}\text { Isotropic } \\
\text { shift }\end{array}$ & $\begin{array}{c}\mathrm{S}_{\text {ISO TMS- }} \\
\mathrm{S}_{\text {iso }} \text { atom }\end{array}$ & $\Delta \delta$ & $\begin{array}{c}\text { Isotropic } \\
\text { shift }\end{array}$ & $\begin{array}{c}\mathrm{S}_{\mathrm{ISO}} \mathrm{TMS}- \\
\mathrm{S}_{\text {iso }} \text { atom }\end{array}$ & $\Delta \delta$ \\
\hline 1 & 75.42 & 126.29 & -107.16 & 82.10 & 119.61 & -182.11 \\
\hline 2 & 83.07 & 118.64 & -173.55 & 88.67 & 113.04 & -144.77 \\
\hline 3 & 68.87 & 132.84 & -157.39 & 70.01 & 131.7 & -124.73 \\
\hline 4 & 25.71 & 7.2 & -23.38 & 26.12 & 6.79 & -23.17 \\
\hline 5 & 61.29 & 140.42 & -102.68 & 58.61 & 143.10 & -161.06 \\
\hline 6 & 87.40 & 114.31 & -171.54 & 91.95 & 109.76 & -202.63 \\
\hline 7 & 165.91 & 35.80 & -152.7 & 166.18 & 35.54 & -166.84 \\
\hline 8 & 280.25 & - & - & 275.30 & - & - \\
\hline 9 & 62.67 & 139.04 & -130.65 & 65.80 & 135.91 & -144.13 \\
\hline 10 & 159.10 & 42.61 & -139.04 & 157.48 & 44.23 & -163.69 \\
\hline 11 & 284.86 & - & - & 282.69 & - & - \\
\hline 12 & 25.62 & 7.29 & -16.99 & 26.50 & 6.41 & -17.29 \\
\hline 13 & 30.59 & 2.32 & -31.18 & 30.83 & 2.08 & -24.20 \\
\hline 14 & 30.15 & 2.76 & -26.48 & 29.82 & 3.09 & -32.66 \\
\hline 15 & 28.46 & 4.45 & -19.01 & 28.35 & 4.56 & -21.36 \\
\hline 16 & 549.22 & - & - & 623.61 & - & - \\
\hline 17 & 246.92 & - & - & 241.36 & - & - \\
\hline 18 & 30.42 & 2.45 & -29.22 & 30.15 & 2.76 & -23.68 \\
\hline 19 & 30.27 & 2.64 & -26.79 & 30.02 & 2.89 & -31.89 \\
\hline 20 & 28.14 & 4.77 & -20.26 & 28.96 & 3.95 & -11.78 \\
\hline 21 & 141.89 & 59.82 & -147.65 & 175.83 & 25.88 & -152.42 \\
\hline 22 & $32 . .63$ & 0.26 & -32.40 & 32.35 & 0.56 & -35.83 \\
\hline 23 & 33.03 & -0.12 & -29.76 & 32.76 & 0.15 & -21.69 \\
\hline 24 & 39.60 & 162.11 & -46.82 & 155.26 & 46.45 & -145.19 \\
\hline 25 & 238.63 & - & - & 30.18 & 2.73 & -26.62 \\
\hline 26 & 28.92 & 3.95 & -30.13 & 29.82 & 3.09 & -28.83 \\
\hline 27 & 187.31 & - & - & 182.54 & - & - \\
\hline 28 & -21.28 & - & - & 30.14 & 171.57 & -24.41 \\
\hline 29 & 31.99 & 0.92 & -26.01 & 28.15 & 4.76 & 27.1 \\
\hline 30 & 31.92 & 0.99 & -26.48 & -163.95 & - & - \\
\hline 31 & - & 5.41 & -22.99 & 162.17 & - & - \\
\hline 32 & - & - & - & 36.69 & 165.02 & -158.99 \\
\hline 33 & - & - & - & 28.99 & 3.92 & -21.96 \\
\hline 34 & - & - & - & 178.01 & 23.69 & -156.9 \\
\hline 35 & - & - & - & -117.84 & - & - \\
\hline 36 & - & - & - & 26.81 & 6.1 & -31.06 \\
\hline 37 & - & - & - & 30.37 & 2.54 & -22.59 \\
\hline 38 & - & - & - & 31.01 & 1.9 & -30.49 \\
\hline 39 & & - & - & 31.07 & 1.84 & -32.44 \\
\hline
\end{tabular}

Table 9. Isotropic shift, relative (to TMS) shifts in ppm for ${ }^{13} \mathrm{C}$ NMR of using GIAO method at HF and B3LYP functional using basis set 6-31g* adducts and dopamine.

\begin{tabular}{|l|l|c|c|c|c|c|c|c|}
\hline \multirow{2}{*}{ Atom } & \multicolumn{3}{|c|}{ 5-S-glutathionyldopamine } & \multicolumn{2}{c|}{ 5- $S$ - - acetylcysteinyldopamine } & \multicolumn{2}{c|}{ Dopamine } \\
\cline { 2 - 9 } & HF & B3LYP & Exp. & HF & B3LYP & Exp. & HF & B3LYP \\
\hline $\mathrm{CH}_{2} \mathrm{CH}_{2} \mathrm{NH}_{2}$ & 44.08 & 47.30 & 43.5 & 35.5 & 22.77 & 32.9 & 35.9 & 41.7 \\
$\mathrm{SCH}_{2}$ & 32.54 & 49.95 & 35.5 & 35.9 & 35.81 & 35.1 & 42.9 & 46.9 \\
$\mathrm{C}-2$ & 110.56 & 124.91 & 117.6 & 109.8 & 122.01 & 117.7 & 117.8 & 109.2 \\
$\mathrm{C}-5$ & 113.29 & 143.73 & 120.1 & 113.0 & 104.5 & 119.9 & 140.7 & 137.4 \\
$\mathrm{C}-6$ & 117.51 & 116.79 & 126.5 & 119.6 & 128.31 & 126.7 & 115.7 & 112.3 \\
$\mathrm{C}-1$ & 132.67 & 133.33 & 130.0 & 131.7 & 117.74 & 130.0 & 133.2 & 130.4 \\
$\mathrm{C}-3$ & 136.03 & 124.93 & 144.9 & 135.9 & 117.70 & 144.9 & 111.9 & 107.2 \\
$\mathrm{C}-4$ & 142.87 & 139.34 & 145.4 & 143.1 & 100.01 & 146.4 & 134.7 & 133.0 \\
\hline
\end{tabular}

Bull. Chem. Soc. Ethiop. 2010, 24(2) 


\section{CONCLUSIONS}

For a long time, electrochemical oxidation has proved to be an efficient tool for the generation of highly electrophilic quinines species, which can be further scavenged by diverse nucleophilic entities such as thiol groups. Accordingly, unstable o-quinone species have been electrogenerated from catechols and catecholamines such as dopamine, norpinephrine or $\mathrm{N}$ acetyldopamine, and then scavenged by thiol residues to efford the corresponding catecholthioether adduct. (1) The stability of 5-S-glutathionyldopamine was studied by theoretical methods. These calculations are agreement with available experimental data. 5-Sglutathionyldopamine is stable in the presence of biological oxidizing agents such as dioxygen, hydrogen peroxide and superoxide radical. (2) It has been demonstrated that 5-Sglutathionyldopamine is rapidly metabolized in rat brain to 5-S-cysteinyldopamine in reaction mediated by gamma-glutamyl transpeptidase and dipeptidase. Equlibrium constant of this reaction in Table 2 prove this case. (3) When the bond length increases, the bonding strength decrease. Stability constants in Table 2 prove this case. (4) Geometrical parameters and charge calculations show that these reactions proceed through the 1,4-Michael addition mechanism. Amines and thiols groups react by a nucleophilic attack at position 5 of dopamine ring. The charges on $\mathrm{C}_{5}$ are less than $\mathrm{C}_{6}$ in compounds. Then, the basisity of $\mathrm{C}_{5}$ is more than $\mathrm{C}_{6}$ (Table 4 ). (5) Charges on $\mathrm{C}_{5}$ are increased to negative values in 5-S-glutathionyldopamine. (6) The pcharacter of sulfur $\sigma_{\text {Cring-S }}$ in 5-S-glutathionyldopamine $\left(\mathrm{sp}^{12.47}\right)$ is bigger than 5-Scysteinyldopamine $\left(\mathrm{sp}^{5.51}\right)$. Similarly, C-S bond length is bigger in 5-S-glutathionyldopamine. Since in this reaction two particles form one, should have a negative value. (7) Calculations showed that methylation cause to increase $C_{5}$ charge in HHMA. Therefore, the basicity of $\mathrm{C}_{5}$ increases with methylation. (8) Calculations show that methylation cause to decrease of activation energy of oxidation reaction. (9) Also in 5-S-cysteinyldopamine the difference of atom charge of $C_{21}$ and sulfur is very less. Therefore the bonds become weaker. (10) The electrons transfer from HOMO to LUMO in 5-S-glutathionyldopamine is relatively easier than that in 5-S-cysteinyldopamine. (11) LUMO in 5-S-cysteinyldopamine accepts electrons easier than 5-S-glutathionyldopamine. (12) From the resulting data shown in Table 5, it is obvious that the LUMO energies of quinones are lower than those of dopamine and HHMA. (13) Energy gap of quinones is smaller than that of dopamine and HHMA and consequently, the electrons transfer from HOMO to LUMO in quinones is relatively easier than that in dopamine and HHMA. (14) With the decrease of the LUMO energies, LUMO in quinones accept electron easily. (15) Calculations show that methylation cause to decrease of the LUMO energies, LUMO in HHMA and HHMA-o-quinone accept electron easier than dopamine and dopamine$o$-quinone. (16) Highest occupied molecular orbital (HOMO), the lowest unoccupied molecular orbital (LUMO) and HOMO and LUMO energy gaps, dipole moment $(\mu)$, ionization potential (I), electron affinity (A), absolute electronegativity $(\chi)$ and absolute hardness $(\eta)$ have changed in water. (17) NMR calculation yielded molecular geometries in good agreement with available experimental data. NMR analysis of dopamine $o$-quinone-cysteine and dopamine $o$-quinoneglutathione conjugates revealed that addition of cysteine and glutathione were at C-5 to form 5S-cysteinyldopamine and 5-S-glutathionyldopamine, respectively.

\section{REFERENCES}

1. Tse, D.C.; McGreery, R.L.; Adams, R.N. J. Med. Chem. 1976, 19, 37.

2. Graham, D.G. Mol. Pharmacol. 1978, 14, 633.

3. Shen, X.M.; Dryhurst, G. Chem. Res. Toxicol. 1996, 9, 751.

4. Fornstedt, B.; Carlsson, A. Neuropharmacology 1991, 30, 463. 
5. Spencer, P.; Jenner, P.; Daniel, S.E.; Lees, A.J.; Marsden, D.C.; Halliwell, B. J. Neurochem. 1998, 71, 2112.

6. Cheng, F.C.; Kuo, J.S. J. Neural. Transm. 1996, 103, 433.

7. Carstam, R.; Brinck, C. Biochim. Biophys. Acta 1991, 1097, 152.

8. Schwartz, R. H.; Miller, N.S. Pediarics 1997, 100, 705.

9. Walubo, A.; Seger, D. Hug. Exp. Toxical. 1999, 18, 119.

10. Ricaurte, G.A.; McCann, U.D. Lancet 2005, 365, 2137.

11. Monks, T.J.; Jons, D.C. Drug Monit. 2004, 26, 132.

12. Segura, M.; Jordi, O. Chem. Res. Toxicol. 2001, 14, 1203; (b) Glendening, E.D.; Weinhold, F. J. Comput. Chem. 1998, 19, 628.

13. Levine, I.N. Quantum Chemistry, Prentice-Hall: New York; 2000.

14. Frisch, M.J.; Trucks, G.W.; Schlegel, H.B.; Scuseria, G.E.; Robb, M.A.; Cheeseman, J.R.; Znkrzewski, V.G.; Montgomery, G.A.; Startmann, R.E.; Burant, J.C.; Dapprich, S.; Millam, J.M.; Daniels, A.D.; Kudin, K.N.; Strain, M.C.; Farkas, O.; Tomasi, J.; Barone, V.; Cossi, M.; Cammi, R.; Mennucci, B.; Pamelli, C.; Adamo, G.; Clifford, S.; Ochterski, J.; Petersson, G.A.; Ayala, P.Y.; Cui, Q.; Morokoma, K.; Malick, D.K.; Rubuck, A.D.; Raghavachari, K.; Foresman, J.B.; Cioslawski, J.; Oritz, J.V.; Stlefanov, B.B.; Liu, G.; Liashenko, A.; Piskorz, P.; Komaromi, I.; Comperts, R.; Martin, R.L.; Fox, P.J.; Keith, T.; Al-laham, M.A.; Peng, C.Y.; Akkara, A.N.; Gonzales, C.G.; Combe, M.C.; Gill, P.M.W.; Johnson, B.; Chem, W.; Wong, M.W.; Andres, J.L.; Gonzales, C.; Head-Gordon, M.; Replogle E.S.; Pople, J.A.; Gaussian 98, Revision A. 9, Gaussian Inc.: Pittsburgh PA; 1998.

15. Li, H.; Dryhurst, G. J. Neurochem. 1997, 69, 1530.

16. NBO method: Glendening, E.D.; Reed, A.E.; Carpenter, J.E.; Weinhold; F. J. Chem. Phys. 1983, 78, 4066.

17. Wlinski, K.; Hilton, J.F. J. Am. Chem. Soc. 1990, 112, 8251.

18. Mcweeny R. Phys. Rev. 1996, 104, 5497.

19. Graham, D.G. Mol. Pharmacol. 1978, 14, 633.

20. Zhang, F.; Dryhurst, G. J. Med. Chem. 1994, 37, 1084.

21. Zhang, F.; Dryhurst, G. Chem. Res. Toxicol. 1995, 9, 751.

22. Cheng, F.C.; Kuo, J.S.; Chia, L.G.; Dryhurst, G. J. Neural Transmission 1996, 103, 433.

23. Miller, R.T.; Lau, S.S.; Monks, T.J. Chem. Res. Toxicol. 1995, 8, 634.

24. Okun, M.R.; Donnelan, B. Histochimie 1971, 25, 289.

25. Rosei, M.A.; Blarzino, C.; Foppoli, C.; Mosca, L.; Coccia, R. Biochem. Biophys. Res. Commun. 1994, 200, 344.

26. Hastings, T.G. Nature 1995, 334, 345.

27. D'Ischia, M.; Prota, G. Pigment Cell Research 1997, 10, 370.

28. Bangham, A.D.; Hill, M.W.; Miller, N.G.A. Methods in Membrane Biology, Plenum Press: London; 1974; pp 1-68.

29. Buege, J.; Aust, S.D. Methods in Enzymology, Vol. 52C, Academic Press: New York; 1978; p 302.

30. Gibian, M; Vandenberg, P. Anal. Biochem. 1987, 163, 343.

31. Miertus, S.; Tomasi, E. J. Chem. Phys. 1981, 55, 117. 